\title{
Testing and Analysis of Induction Motor Electrical Faults Using Current Signature Analysis
}

\author{
K. Prakasam, S. Ramesh \\ Department of EEE, K.S.R. College of Engineering, Tiruchengode, India \\ Email: prakasameee@gmail.com
}

Received 2 May 2016; accepted 20 May 2016; published 28 July 2016

Copyright (C) 2016 by authors and Scientific Research Publishing Inc.

This work is licensed under the Creative Commons Attribution International License (CC BY). http://creativecommons.org/licenses/by/4.0/

(c) (i) Open Access

\begin{abstract}
The proposed method deals with the emerging technique called as Motor Current Signature Analysis (MCSA) to diagnosis the stator faults of Induction Motors. The performance of the proposed method deals with the emerging technique called as Motor Current Signature Analysis (MCSA) and the Zero-Sequence Voltage Component (ZSVC) to diagnose the stator faults of Induction Motors. The unalleviated study of the robustness of the industrial appliances is obligatory to verdict the fault of the machines at precipitate stages and thwart the machine from brutal damage. For all kinds of industry, a machine failure escorts to a diminution in production and cost increases. The Motor Current Signature Analysis (MCSA) is referred as the most predominant way to diagnose the faults of electrical machines. Since the detailed analysis of the current spectrum, the method will portray the typical fault state. This paper aims to present dissimilar stator faults which are classified under electrical faults using MCSA and the comparison of simulation and hardware results. The magnitude of these fault harmonics analyzes in detail by means of Finite-Element Method (FEM). The anticipated method can effectively perceive the trivial changes too during the operation of the motor and it shows in the results.
\end{abstract}

\section{Keywords}

Three Phase Induction Motor, Motor Current Signature Analysis (MCSA), ZSVC, Fault Diagnosis, Current Spectrum Analysis

\section{Introduction}

Induction motors are a popular energy conversion component of many industrial processes and are frequently 
integrated with commercially available equipment and industrial processes. However, these machines will have a wider chance to fail because of heavy duty cycles, installation, poor working environment, improper excitation and manufacturing factors, etc. With increasing demands for efficiency and reliability, the field of fault diagnosis in induction motors is gaining importance [1]-[3]. There are plentiful methods are presented in existing like based on chemical monitoring, machine pulsation (vibration) monitoring, thermal monitoring, aural secretion monitoring, but all have necessitate of exclusive dedicated sensors or equipments to obtain the specific gesture to process, whereas in this projected current monitoring procedure there is no supplementary sensors required [2]. This is because of the fundamental electrical quantities linked with electromechanical industries such as voltage and currents are voluntarily deliberated by tapping into existing voltage and current transformers at the protection system. In this way, considering the advantages and reduced costs, non-invasive methods have been preferred for practical purposes. During the typical operating stage of the induction motor a combination of faults may occur. If these faults are undetected can at the right time or initially, then it leads to create a possible catastrophic failure [4]. Therefore, a diversity of stipulation monitoring schemes was introduced for an analysis of unexpected surroundings.

The electrical faults and mechanical faults of the induction motors are the two groups of faults which are derived from common internal faults. Based on the fault occurred in the induction motor, the electrical faults have been classified in two ways in industries like stator faults and rotor faults. The stator faults are the primary and a critical one to diagnose, hence the stator faults are only taken into account in this study. The distinctive faults are scheduled as revealed in Figure 1. In an impartial three phase induction motor a stator short circuit fault between turn to turn causes a vast circulating current to pour and afterward engender excessively much heat in the shorted winding turns is measured as an earlier kind of fault in the given three phase induction motor [4] [5]. After that, the inter-turn short circuit is the immediate type of fault inspected in this manuscript.

The stator winding inter-turn short circuit is the preface fault point for winding faults such as turn loss in the stator windings of the three phases. The stimulates harmonic frequencies in a three phase induction machine stator current as:

$$
f_{\text {stator }}=\left\{\frac{n}{p}(1-s) \pm k\right\} f_{1}
$$

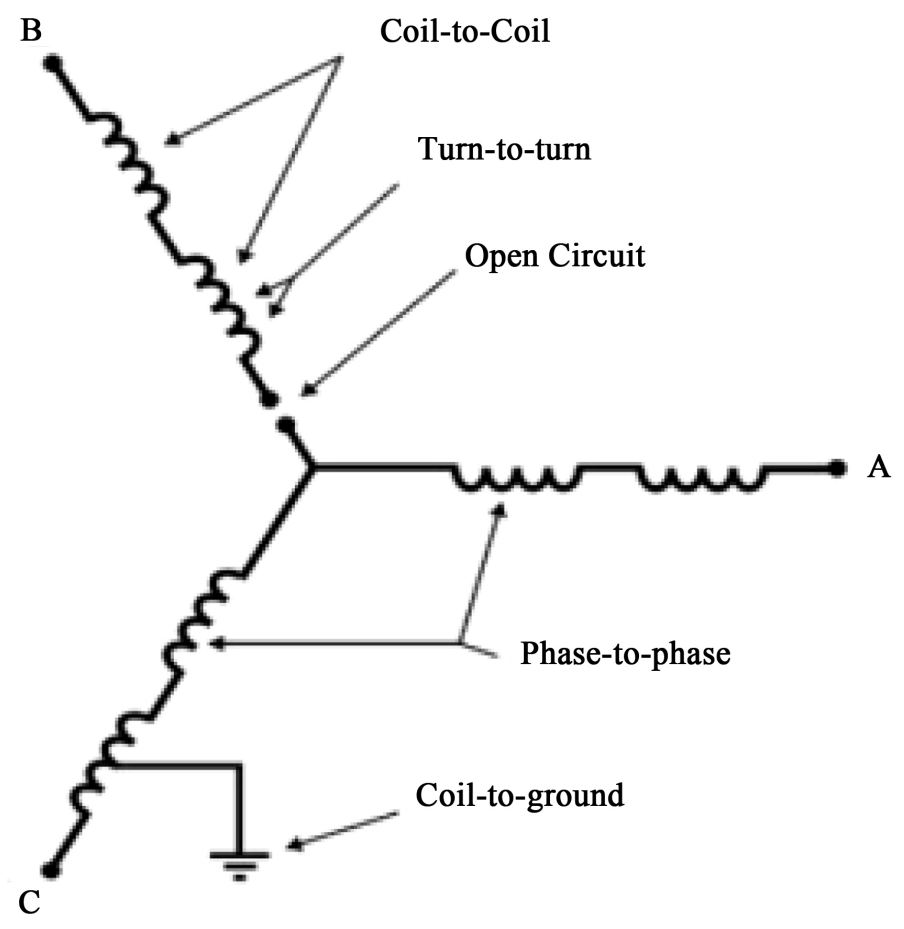

Figure 1. Typical faults in stator winding. 
where $p$ is the number of pole pairs in the stator side, $n=1,2,3, \cdots$, and $k=1,3,5, \cdots$, likewise.

With sinusoidal mmf the stator slot harmonic frequency element for the stator current can be expressed as:

$$
f_{\text {stator }}=\left\{z_{2}(1-s) \frac{f_{1}}{p} \pm f_{1}\right\}
$$

$Z$ being the rotor slot numbers.

To attain three phase induction motor stator winding mmf time harmonic into account, $f_{1}$ is multiplied with harmonic figure of the stator winding mmf in time harmonics and it is indicated by $h,(h=1,3,5,7, \cdots)$.

The slot harmonic frequency $\left(f_{h}\right)$ for the stator winding current will arrive out as

$$
f_{h}=\left\{z_{2}(1-s) \frac{f_{1}}{p} \pm h f_{1}\right\}
$$

Fault indicative practices are gaining more significance in any industry since the necessity to swell consistency and to shrink the leeway of manufacture loss due to machine collapse. By the way of evaluating the signals of a machine operation in usual and slip-up conditions, the discovery of faults such as throng unbalance, misalignment, gear disappointment and budding failures of the components, during the online monitoring method, falling the opportunity of ruinous injuries in the machine stator side and downtime can be determined [6]. A several efforts have been made to design and optimize three phases fault-tolerant motor drives. It is recognized that FEM recreation is a dominant and precise tool to explore the special effects of open-circuit as well as short-circuit faults. In that inter-turn faults are one of the mainly common and potentially detrimental stator faults. So, the FEM and the ZSVC are specially utilized to find the inter-turn short circuit faults.

Further practice includes machinery vibration analysis, thermal (temperature) analysis, acoustic noise measurement, torque sketch analysis and magnetic meadow analysis. These practices have need for complicated and luxurious sensors, further electrical and mechanical installations of the equipments, and repeated preservation and are not favored [7].

The utilization of the steady-state spectral elements of the stator winding is one of the most fashionable ways of three phase induction machine condition monitoring. These spectral frequency elements of the stator winding includes electrical quantities like voltage across the points, current flows in the particular area and power drawn and are used to discover inter-turn faults, broken bars (rotor side), eccentricities in the air gap, bearing failures. Right now, countless practices that are supported on steady-state examinations are the MCSA and the Extended Park's Vector Approach (EPVA) [7], as well as an innovative momentary technique that is a mixture of the EPVA and the Discrete Wavelet Transform.

\section{Motor Current Signature Analysis (MCSA)}

The method Motor Current Signature Analysis (MCSA) is used to resolve the operating condition of induction motors without suspending the production. The fluctuations in the motor current can be observed by clamping a hall effect current sensor. MCSA concentrates its efforts in the spectral analysis of the stator current and has been successfully applied to perceive abnormal levels of the condition of stator windings like open circuit fault, turn-turn, coil-coil, leakage faults, eccentricity in the air-gap and broken bars in the rotor side among other mechanical troubles [8]. The key purpose of the current spectral analysis is to analyze the stator current in search of current harmonics frankly associated with new-fangled rotating flux components, which are caused by trouble in the motor-flux circulation.

For analyzing or trending dynamic energized scheme the motor current signature analysis is used. The results of MCSA support in the discovery of the following:

1) Health of the incoming winding

2) Rotor Health

3) Eccentricity in the air gap

4) Shaft coupling health (with direct, belted and geared systems)

5) Issues due to load

6) Mechanical Bearing health

The real time graphical results and the comparison of numerical values of simulation and hardware results are stated in table for analyzing the proposed work. 


\section{System Specifications}

The proposed work deals three phase squirrel cage Induction Motor testing with the help of LabVIEW software to predict the typical faults which are artificially introduced into the machine. Figure 2 shows the typical winding arrangements made in the specially wounded induction motor for analyzing the proposed work. A three phase squirrel cage induction motor is chosen for this study and the specifications are listed in Table 1.

The above specified machine is specially wounded and takes the number of outlet terminals to make the faults and testing of the machine as shown in Figure 4.

\section{Hardware Description of Fault Diagnosis}

A personal computer based DAQ system is plugged in for the permutation of the computer with the signal from induction motor. It shows the real time attribute of the investigational induction motor during its operation. Beside giving the graphical outlook to the addict, LabVIEW also gives a superior analysis capability about the measurements on the induction motor in the proposed system. The real time working model of the induction motor is designed with PC and LABVIEW interfaced system is depicted in Figure 3 and the specially wounded Induction motor is depicted in Figure 4.

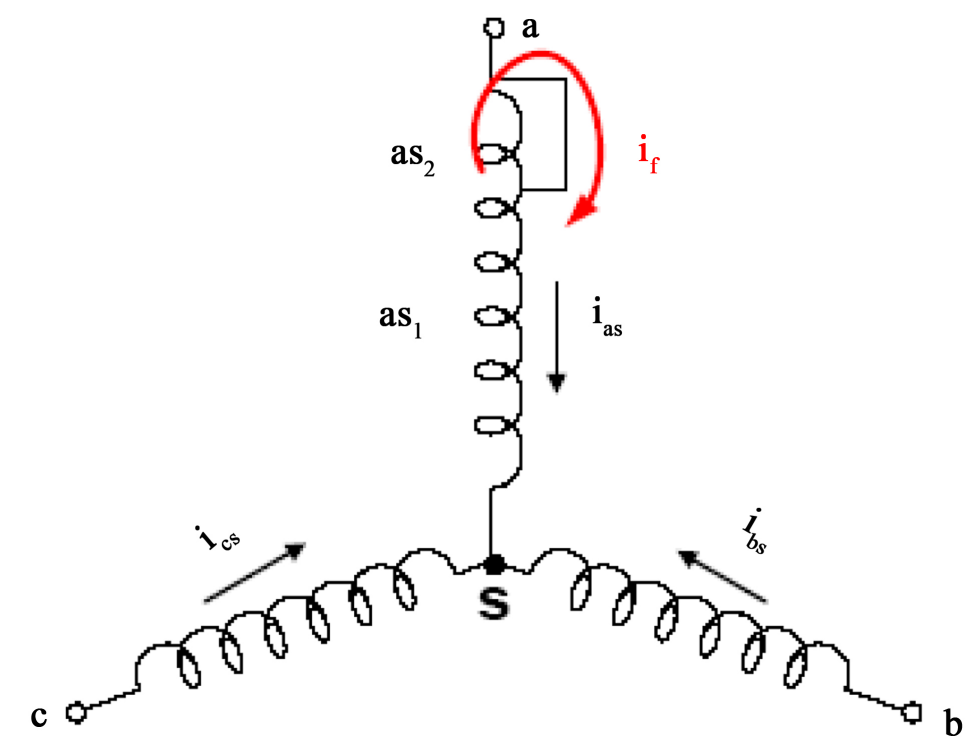

Figure 2. Typical stator winding connection and current flow.

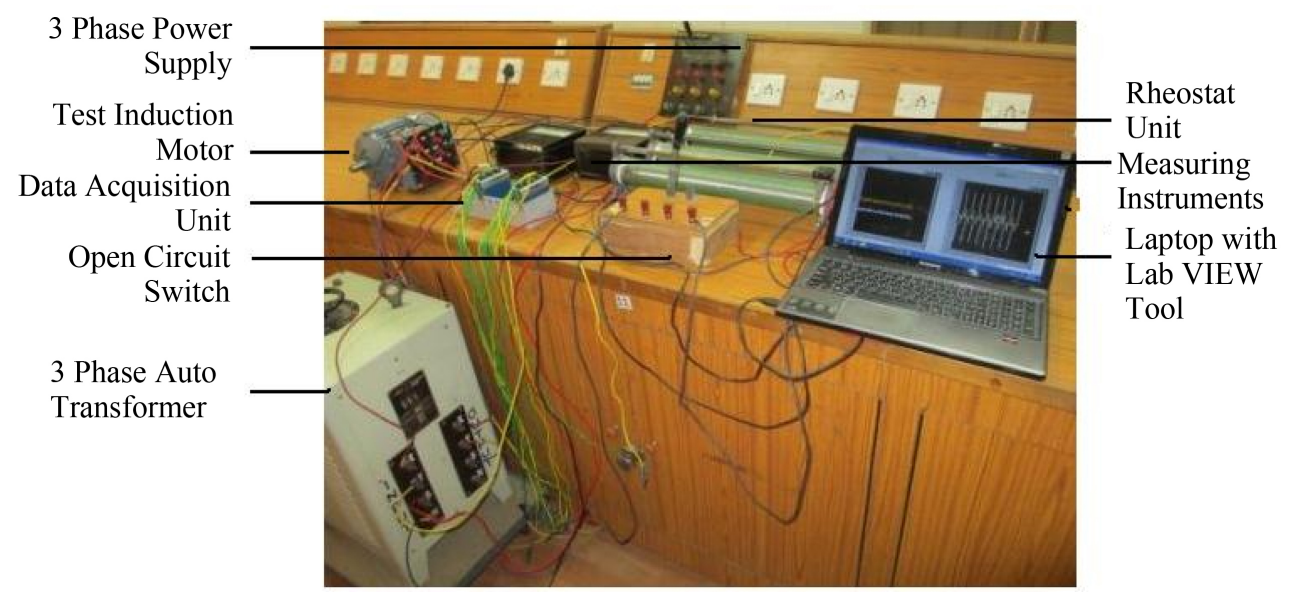

Figure 3. Hardware setup of the proposed system. 


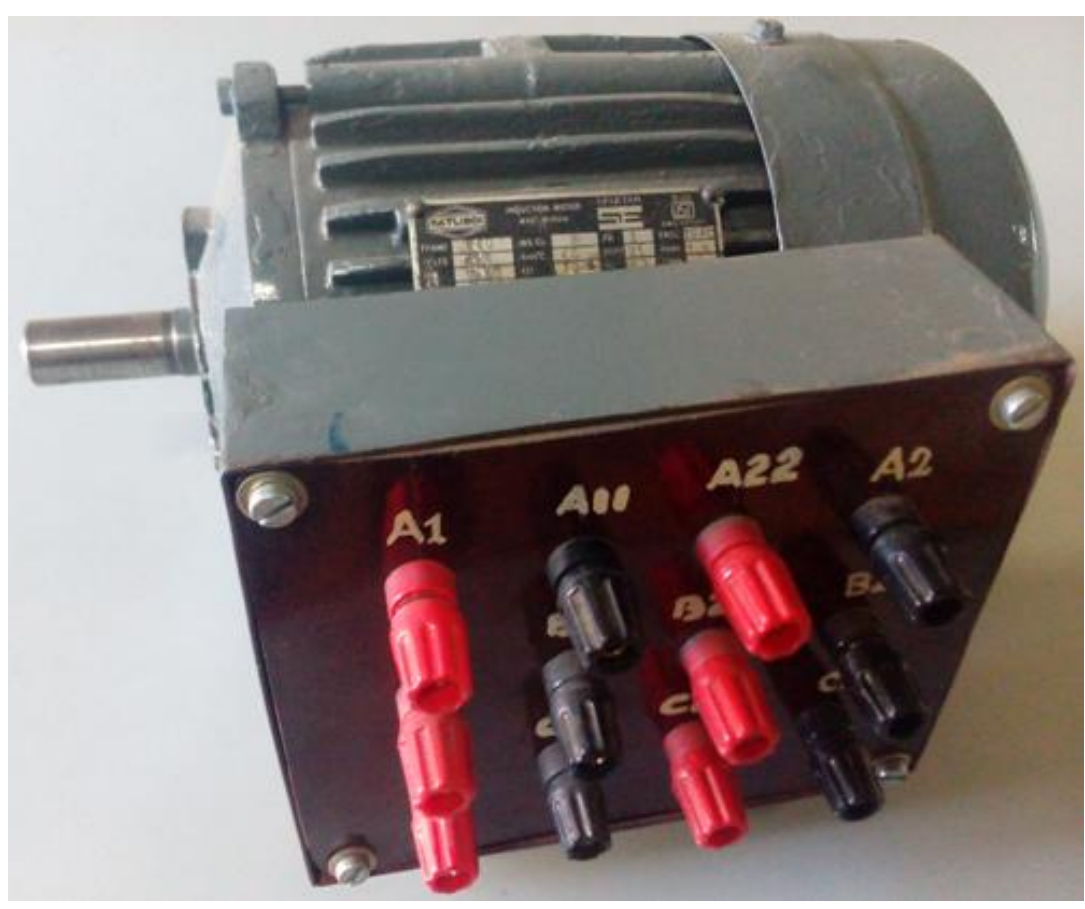

Figure 4. Specially wounded induction motor and its terminal box.

Table 1. 0.75 HP 3 phase induction motor characteristics.

\begin{tabular}{cc}
\hline Description & Range \\
\hline Power (hp) & 0.75 \\
Voltage (V) & $200 / 415$ \\
Current (I) & $3.34 / 1.6$ \\
Speed (N) & 1390 \\
Phases & 3 \\
No. of Poles & 4 \\
No. of Coils per Phase & 12 \\
Types of Stator Winding & Double Layer, Lap \& Y Connected \\
No. of Stator Slots & 36 \\
Make & Spartan Electricals, Bombay \\
\hline
\end{tabular}

The current signature of the induction motor is acquired from each phase of the power supplied to the Induction Motor. Analysis of the current signature is carried out as a co-simulation in LabVIEW. Graphical waveforms of healthy and faulty motors and comparison of their respective signatures are accomplished with the help of LabVIEW tools for different ratings of Induction Machines. In order to create faults in the motor the different control strategy were used [6]-[9].

In this system, voltage spectrum, current spectrum and ZSVC spectrum were measured. The graphical results for different fault conditions are observed and the deficiency between the normal operating condition and the fault conditions were encountered.

\section{Results and Discussion}

The specially wounded Induction Motor has a nine number of external terminals to create the faults artificially on the outside of the Induction Motor. Based on the terminals connected the output current spectrum of the motor 
with each of open circuit, short circuit and leakage faults are presented here.

\subsection{Waveform of Healthy Motor}

The electrical signatures of the stator winding is observed on the healthy machines ought to be clear as per the basic concepts. It is not practically possible to observe the clear signatures. Because, due to line fluctuations and inductive load effects of the induction machine, it also has some fluctuations. Under no-load operating condition this wave form is acquired and shown in Figure 5 and Figure 6. The graphical representation shows the three parameters like voltage, current and fault current. There is no fault current for this case so, the representation shows the huge distortion as shown in Figure 7.

\subsection{Open Circuit Fault}

The open circuit faults arise due to aging, high swiftness applications and mechanical anxiety cut off of any of the winding presented in the stator winding. The voltage of the opened phase directly goes to zero and other phases are pretentious by noise and induction effect as shown as fluctuations. The results were depicted with each phase opened and the waveform is shown in Figures 8-10.

\subsection{Coil-Coil Short Circuit Fault}

On the stator winding, turn-to-turn or turn-to-earth incidences cause the leakage current faults. This is the premature fault stage of open circuit and short circuit faults of the stator windings. This result causes the irregular voltage and currents spectrums in all the three phases and build noise, temperature and varies with the rotor velocity. The similar faulty spectrum is observed if leakage occurring at any of the stator winding phases. Winding may experience short circuit, whose pretentious signature due to such leakages as shown in Figure 11 and Figure 12.

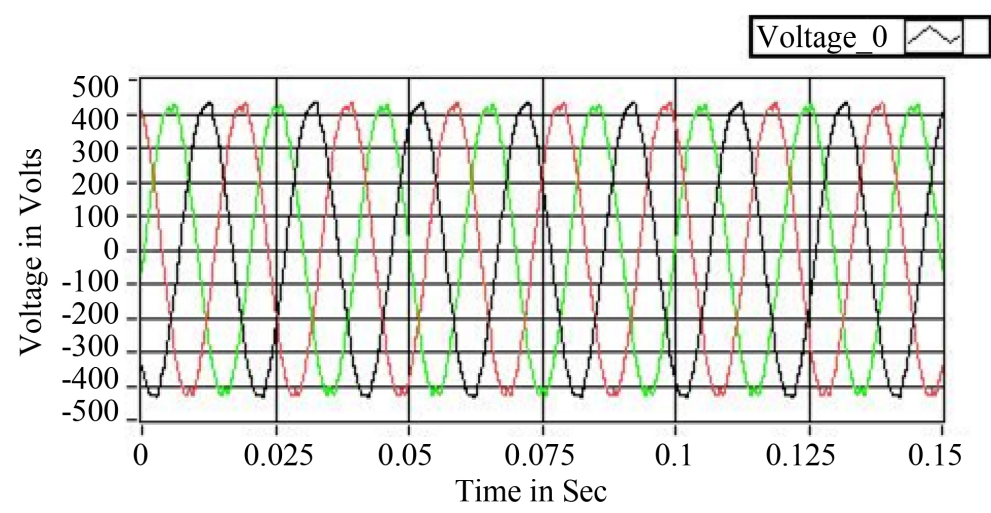

Figure 5. Voltage waveform of healthy induction motor under no-load condition.

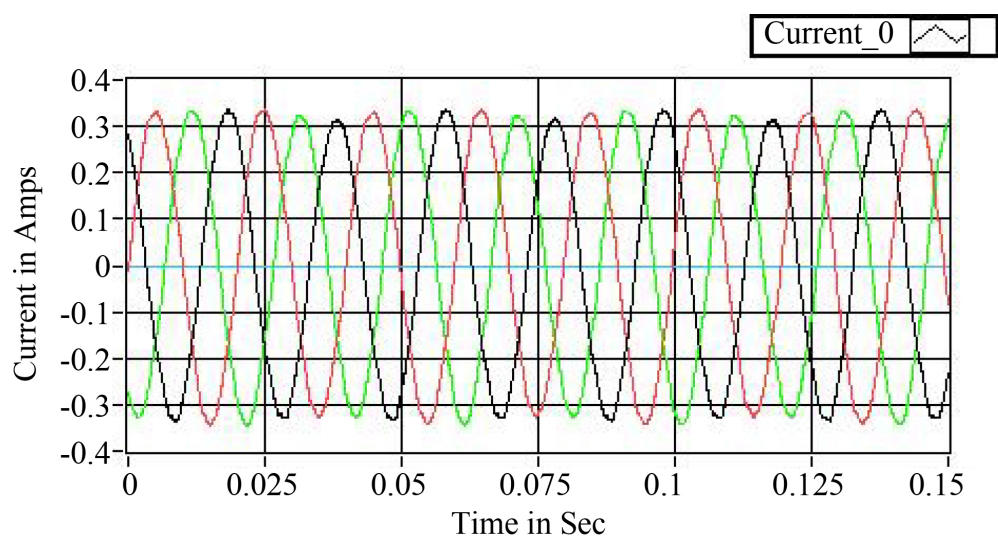

Figure 6. Current waveform of healthy induction motor under no-load condition. 


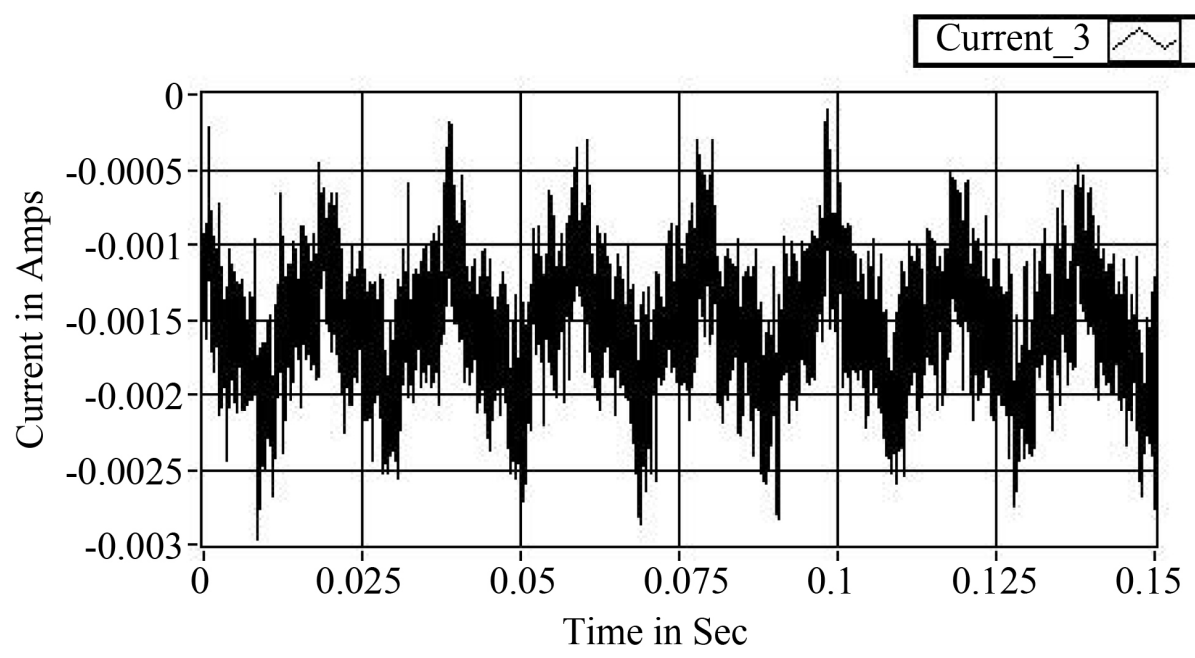

Figure 7. Fault current waveform of healthy induction motor under no-load condition.

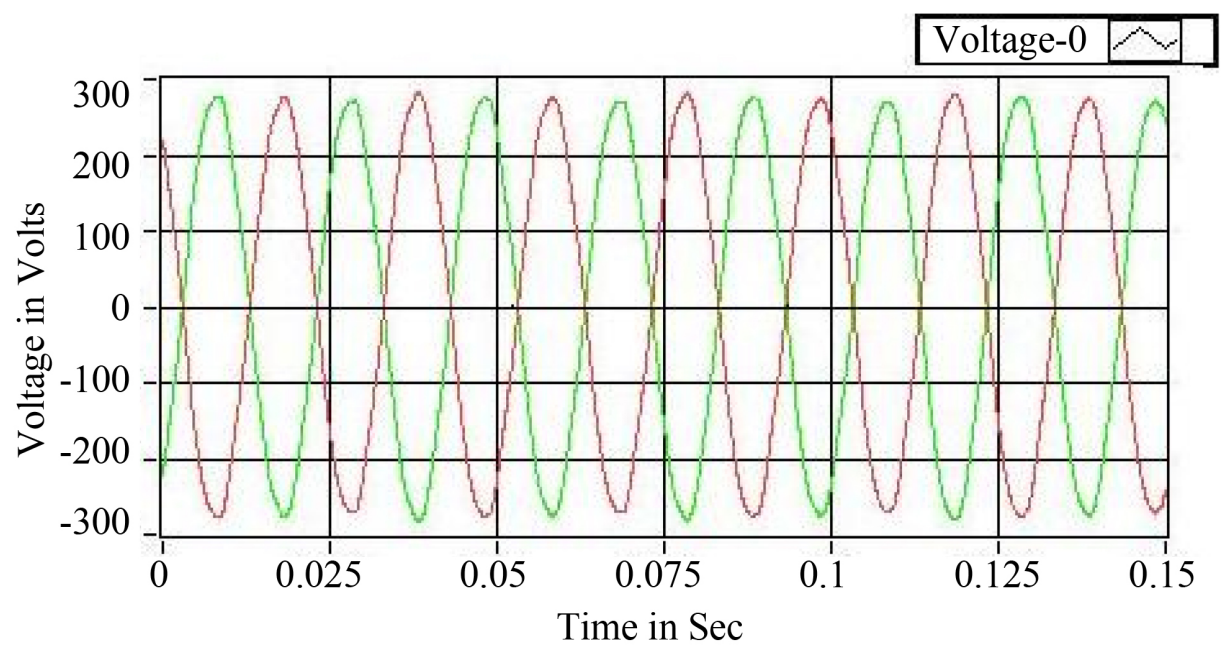

Figure 8. Voltage waveform of the IM with open circuit fault (Phase C opened).

Current_0 $\bigcirc$

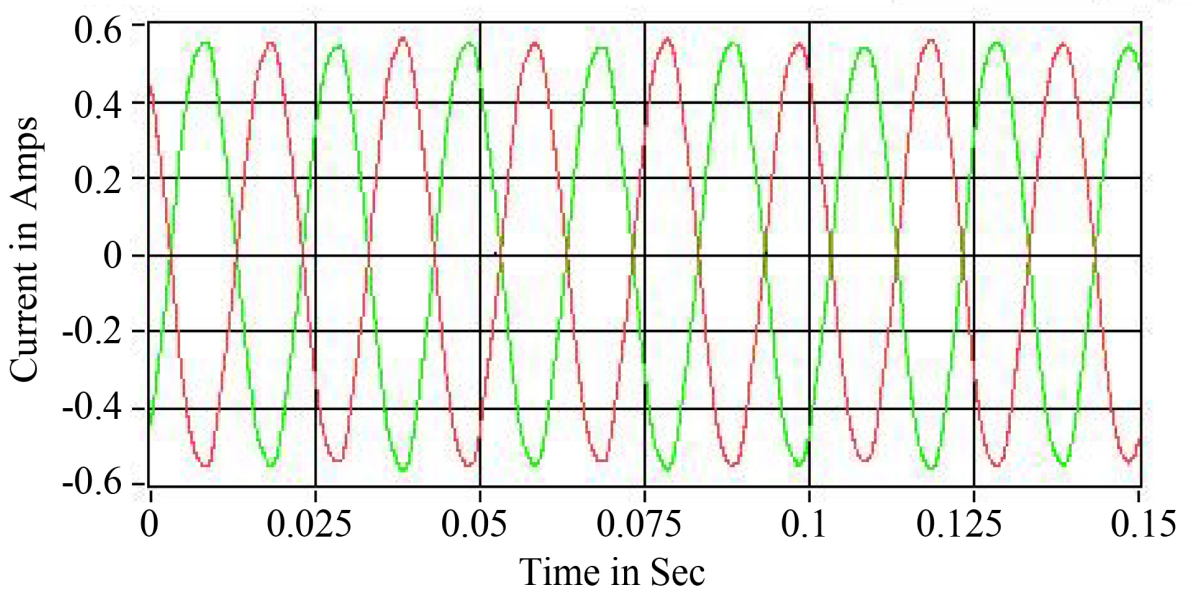

Figure 9. Current waveform of the IM with open circuit fault (Phase C opened). 


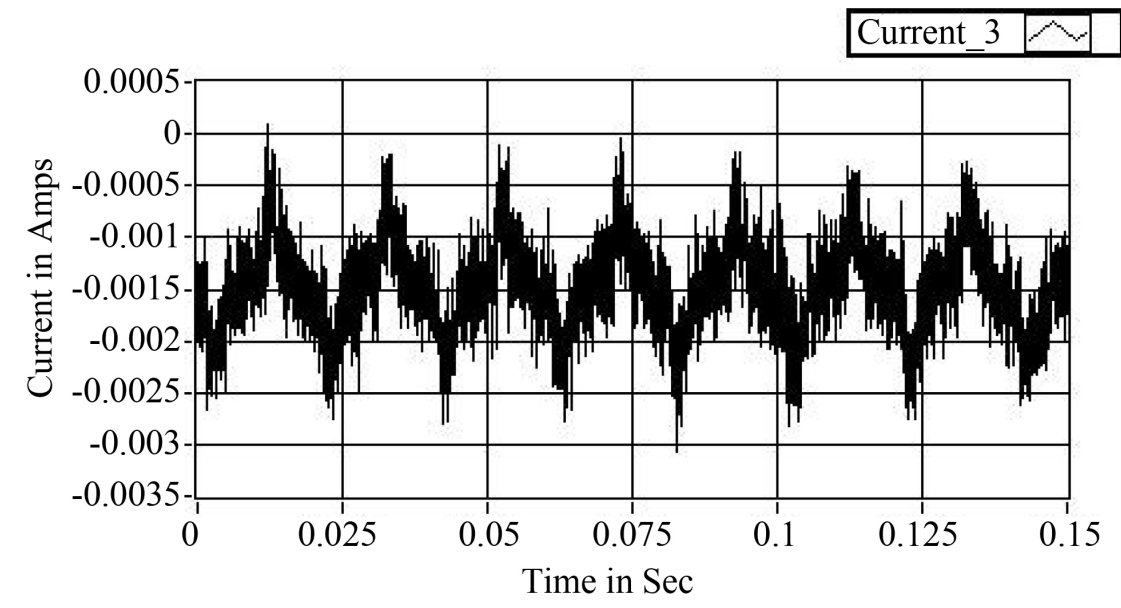

Figure 10. Fault current waveform of the IM with open circuit fault (Phase C opened).

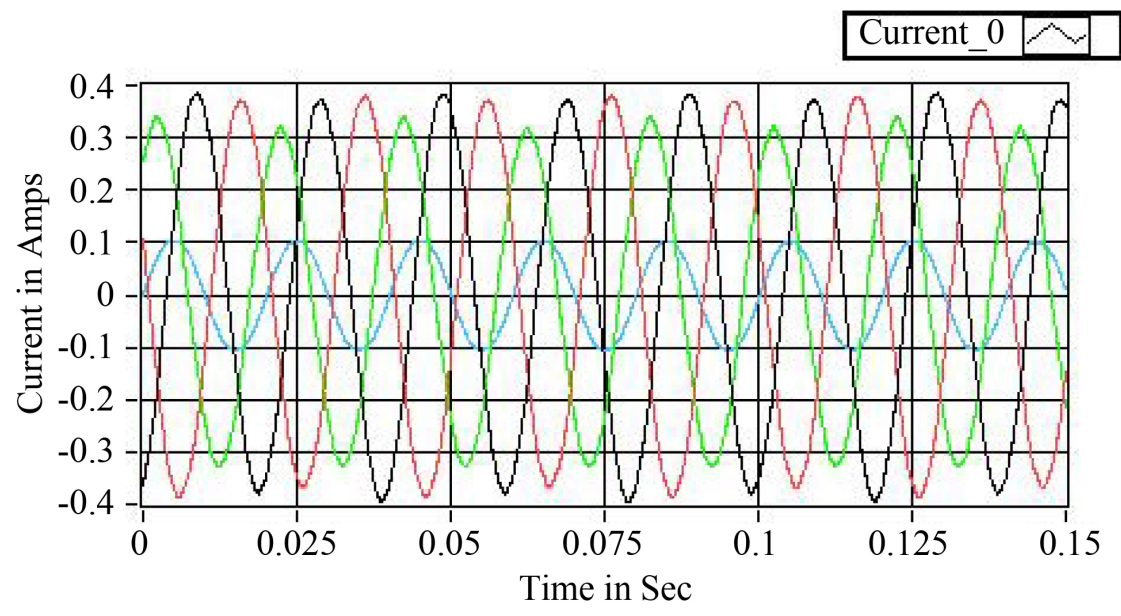

Figure 11. Signature of the faulty IM with leakage fault (Between Phase A \& B).

\subsection{Short Circuit Fault}

The two diverse phases in stator windings may short stick between them. Then the induction motor undergoes a short circuit fault and it allows to flow of up normal current and drop down the voltage resulting in a faulty current spectrum. But in our specially wounded induction motor have a separate lead to make short circuit faults. With the help of those terminals the short circuit is created via the couple of three hundred ohm rheostats is connected in series to avoid dead short circuit conditions. By shorting three dissimilar arrangements of the phases of the induction motor stator windings, the defective output current spectrums are acquired as shown in Figure 13 and Figure 14.

\subsection{Turn-Turn Short Circuit Fault}

The shorting of two turns in the same coil of the same phase in stator windings of the induction motor causes turn-turn short circuit fault. During the short circuit fault condition the current flows through the particular area is in up normal value and the voltage will drop down. The results are observed as voltage, current, faulty current output spectrums and ZSVC spectrums are acquired as shown in Figures 15-20.

Table 2 shows the analytical results of the proposed system between the hardware and the simulation models. The result shows the similarity values are obtained in simulation as well as in hardware. In this table the voltage, three phase current and the fault currents were measured to analyze the parameter variations in the stator side. Based on that the results were compared and conclude that the system gives the accurate values. So, the 


\section{Current $3 \bigcirc$}

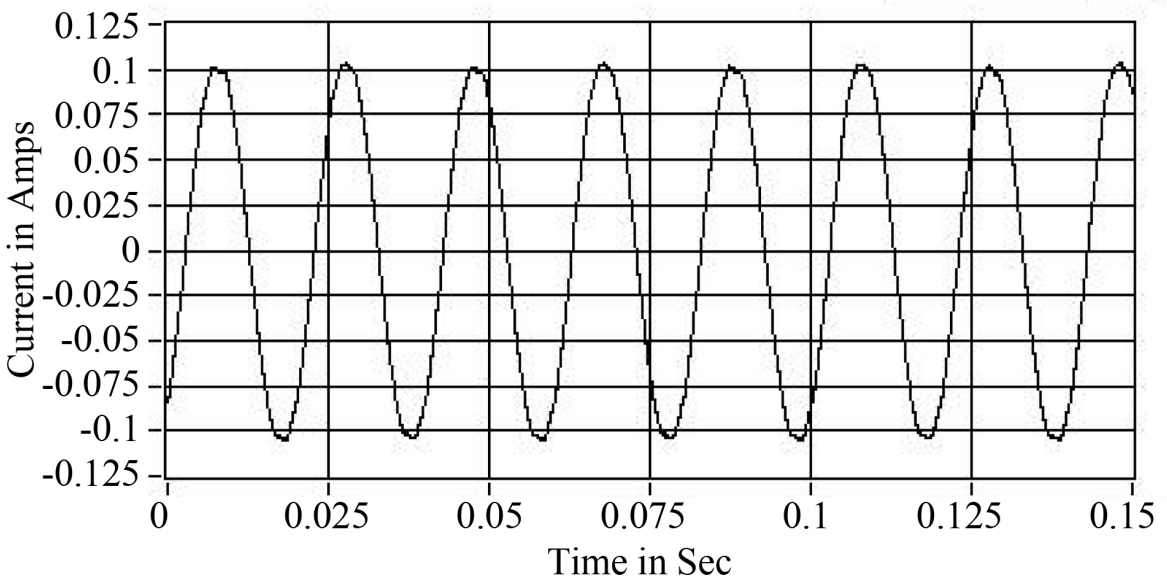

Figure 12. Signature of the faulty IM with leakage fault (Between Phase B \& C).

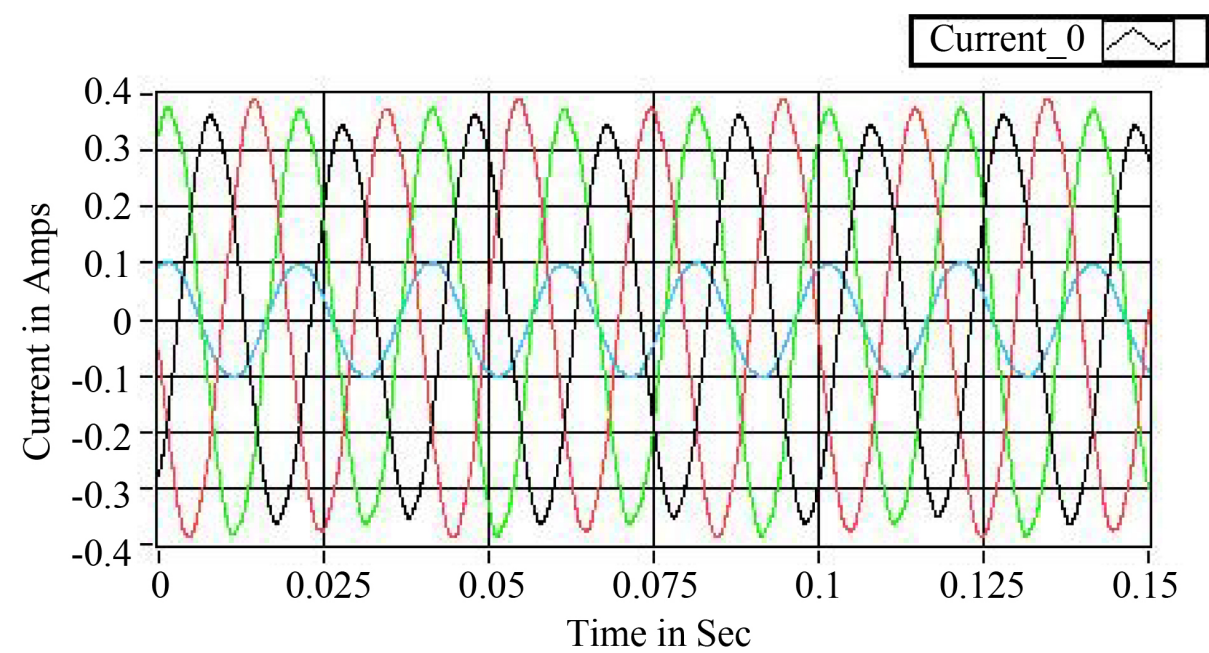

Figure 13. Faulty current spectrum by shorting A \& B phases.
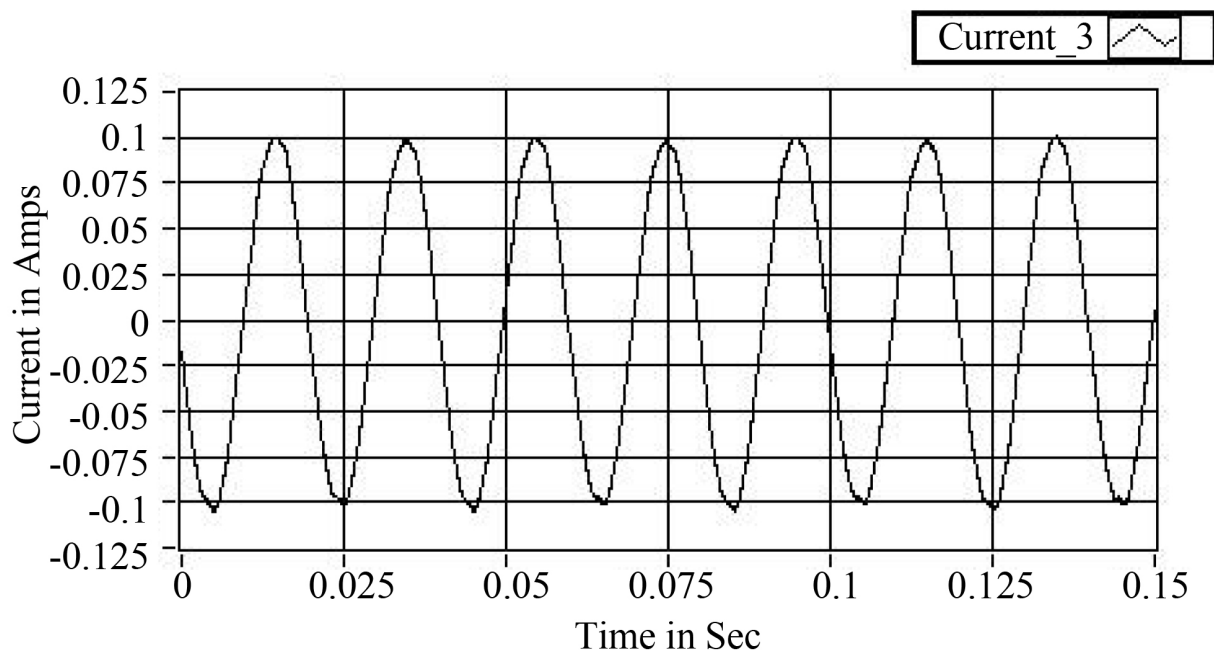

Figure 14. Faulty current spectrum by shorting A \& B phases. 


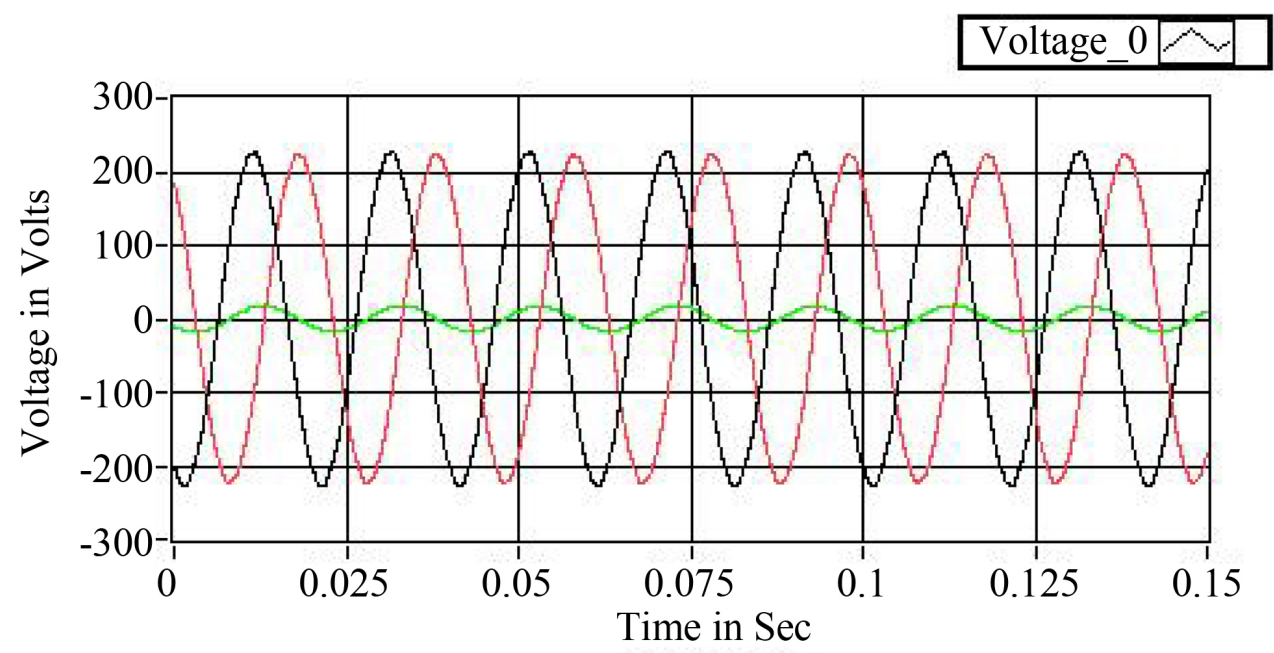

Figure 15. Faulty current spectrum by shorting A \& B phases.

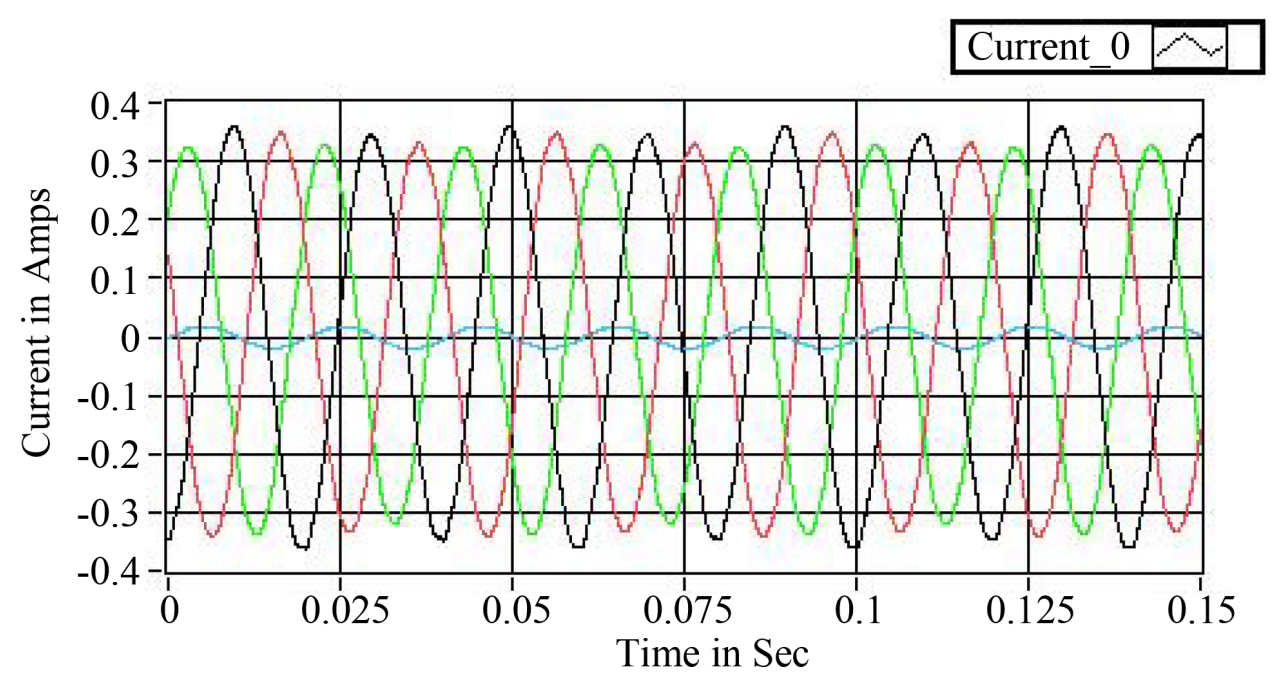

Figure 16. Faulty current spectrum by shorting A \& B phases.

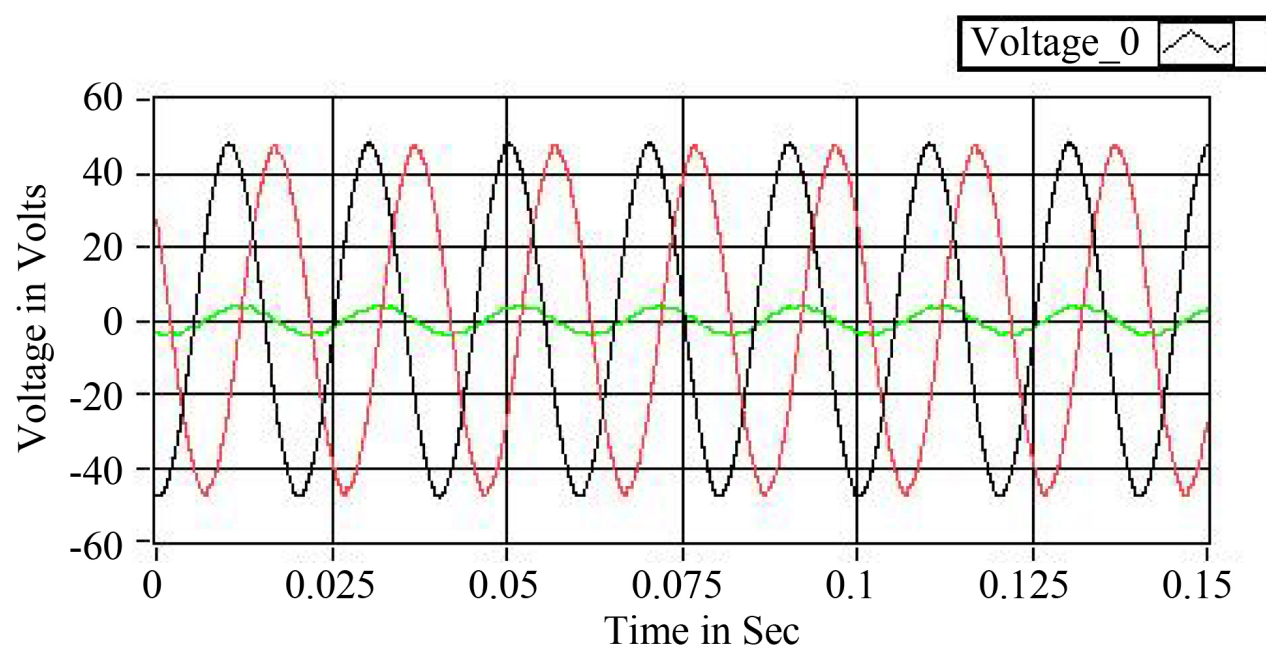

Figure 17. Faulty current Spectrum by shorting A \& B phases. 


\section{Current_3 $\bigcirc$}

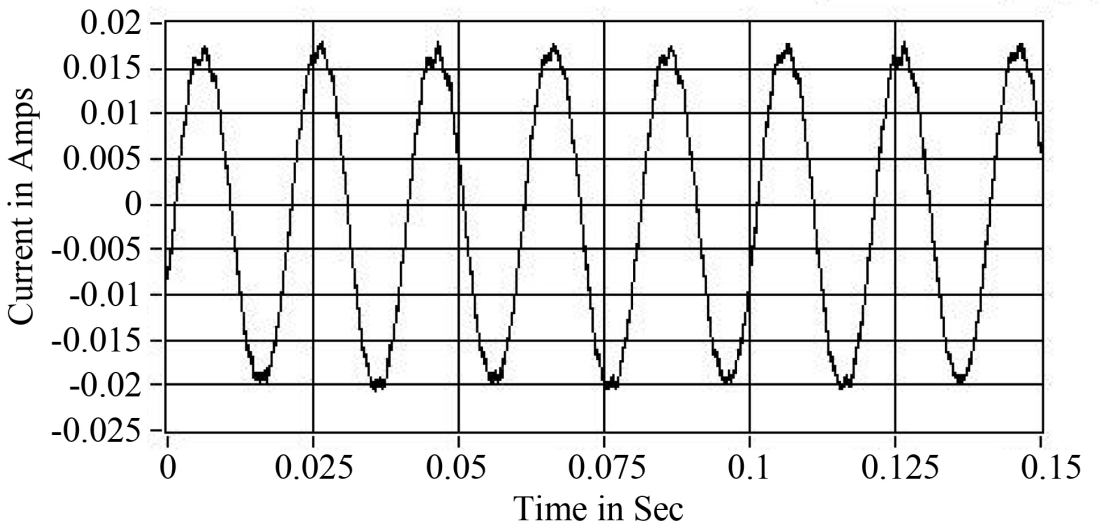

Figure 18. Faulty current spectrum by shorting A \& B phases.

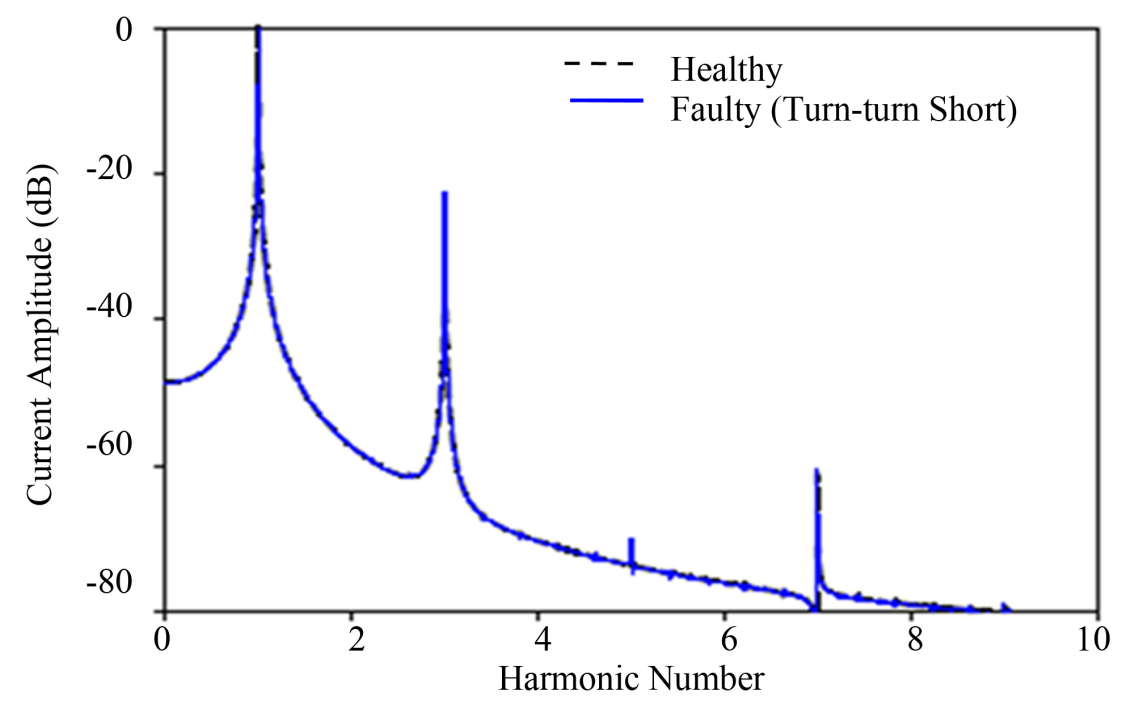

Figure 19. Healthy and faulty current spectra of turn to turn short for one phase.

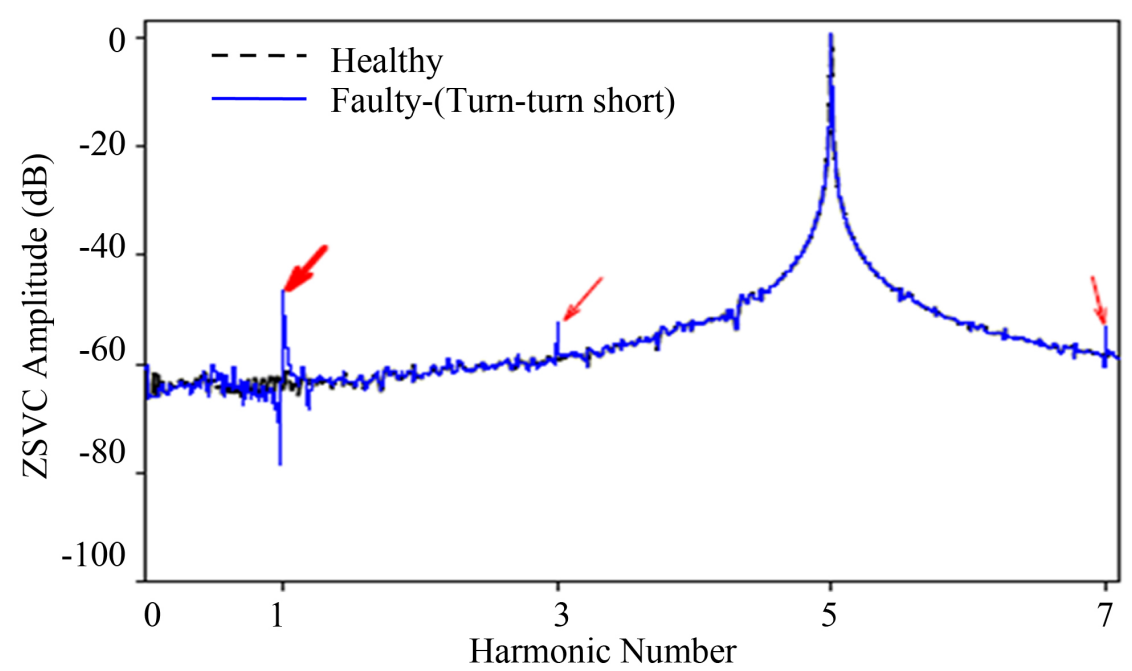

Figure 20. Healthy and faulty ZSVC spectra of turn to turn short for one phase. 
Table 2. Hardware and simulation result comparison.

\begin{tabular}{|c|c|c|c|c|c|c|c|c|c|c|}
\hline \multirow{3}{*}{ Working Condition } & \multicolumn{5}{|c|}{ Hardware } & \multicolumn{5}{|c|}{ Simulation } \\
\hline & \multirow{2}{*}{ 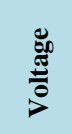 } & \multicolumn{3}{|c|}{ Current } & \multirow{2}{*}{ 馬 } & \multirow{2}{*}{ 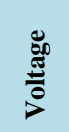 } & \multicolumn{3}{|c|}{ Current } & \multirow{2}{*}{ 氞 } \\
\hline & & $\mathbf{R}$ & $\mathbf{Y}$ & B & & & $\mathbf{R}$ & $\mathbf{Y}$ & B & \\
\hline Normal & 415 & 0.32 & 0.32 & 0.32 & 0.0005 & 415 & 0.33 & 0.33 & 0.33 & 0.0005 \\
\hline Open Circuit & 415 & 0.56 & 0.56 & 0 & 0.0005 & 415 & 0.54 & 0.54 & 0 & 0.0005 \\
\hline Coil-coil short RY & 252 & 0.37 & 0.37 & 0.31 & 0.1 & 250 & 0.35 & 0.35 & 0.29 & 0.09 \\
\hline Phase-phase short RY & 180 & 0.39 & 0.38 & 0.36 & 0.1 & 176 & 0.37 & 0.38 & 0.35 & 0.09 \\
\hline Turn-turn short & 32 & 0.34 & 0.32 & 0.35 & 0.0164 & 31 & 0.33 & 0.31 & 0.34 & 0.0159 \\
\hline
\end{tabular}

proposed system's accuracy was determined.

\section{Conclusion}

Thus the effectiveness of the MCSA method with ZSVC to discover unusual stator faults in the three phase squirrel cage Induction Motor and to discriminate stuck between them has been proved all with its vital rewards. Such as the cleanness of data gaining schemes and the mandatory software, beside with the healthiness of the tools used, which has provided quite acceptable results. Also, the proposed system gives the chance to discover the rotor faults too, like the stator current spectrum analysis. Hence, personal computer aided LabVIEW based on-line condition monitoring system for induction machine was tested and the results were presented in this paper, establishing the efficiency and effectiveness of this method. Also, this projected method has an extensive range of features like on-line MCSA system with artificial intelligence and fault rectification systems, etc. by adding some additional tools in the existing one. The intelligent control tools for the above said hardware systems to improve the performance are in progress and it adds more additional features for this.

\section{Acknowledgements}

The work for this paper was supported by the Coral Rewinding India (P) Ltd. Erode, Tamilnadu, India.

\section{References}

[1] Yeh, C., Sayed, A. and Povinelli, R. (2007) A Reconfigureurable Motor for Experimental Emulation of Stator Winding Inter-Turn and Broken Bar Faults in Poly Phase Induction Machines. IEEE International Electric Machines \& Drives Conference, Antalya, 3-5 May 2007, Vol. 2, 1413-1419. http://dx.doi.org/10.1109/IEMDC.2007.383636

[2] Penman, J., Sedding, H.G., Lloyd, B.A. and Fink, W.T. (1994) Detection and Location of Interturn Short Circuits in the Stator Windings of Operating Motors. IEEE Transactions on Energy Conversion, 9, 652-658. http://dx.doi.org/10.1109/60.368345

[3] Fenger, M., Susnik, M., Laderoute, P. and Thomson, W.T. (2003) Development of a Tool to Detect Faults in Induction Motors via Current Signature Analysis. Proceedings of Cement Industry Technical Conference, 4-9 May 2003, 37-46. http://dx.doi.org/10.1109/citcon.2003.1204707

[4] Neelam, M. and Dahiy, R. (2007) Motor Current Signature Analysis and its Applications in Induction Motor Fault Diagnosis. International journal of systems Applications, Engineering \& Development, 2, 29-35.

[5] Messaoudi, M. and Sbita, L. (2010) Multiple Faults Diagnosis in Induction Motor Using the MCSA Method. International Journal of Signal and Image Processing, 1, 190-195.

[6] Jagadanand, G., Gopi, L., George, S. and Jacob, J. (2012) Inter-Turn Fault Detection in Induction Motor Using Stator Current Wavelet Decomposition. International Journal of Electrical Engineering and Technology (IJEET), 3, 103-122.

[7] Prakasam, K. and Ramesh, S. (2015) Investigation of Induction Motor Stator Faults Using Motor Current Signature Analysis and Multisim. Middle-East Journal of Scientific Research, 23, 277-284.

[8] Bhowmik, P.S., Pradhan, S. and Prakash, M. (2013) Fault Diagnostic and Monitoring Methods of Induction Motor-A Review. International Journal of Applied Control, Electrical and Electronics Engineering (IJACEEE), 1, 1-18.

[9] Bhardwaj, K. and Agarawal, A. (2012) Fault Diagnosis of Three Phase Induction Motor Using Fuzzy Logic Controller and Sequence Analyzer. International Journal of Electrical and Instrumentation Engineering, 2, 112-118. 


\section{Submit or recommend next manuscript to SCIRP and we will provide best service for you:}

Accepting pre-submission inquiries through Email, Facebook, LinkedIn, Twitter, etc.

A wide selection of journals (inclusive of 9 subjects, more than 200 journals)

Providing 24-hour high-quality service

User-friendly online submission system

Fair and swift peer-review system

Efficient typesetting and proofreading procedure

Display of the result of downloads and visits, as well as the number of cited articles

Maximum dissemination of your research work

Submit your manuscript at: http://papersubmission.scirp.org/ 